\title{
A EDUCAÇÃO AMBIENTAL NO CONTEXTO ESCOLAR BRASILEIRO
}

Flávia Helena Cabral Silva Reis ${ }^{1}$ Anna Regina Lanner de Moura ${ }^{2}$

Walter Reis Cabral ${ }^{3}$

Rita de Cássia Mendonça Miranda ${ }^{4}$

Resumo: Este artigo tem como objetivo analisar a Educação Ambiental e seus desdobramentos no contexto escolar brasileiro. Foram selecionadas, das plataformas científicas Google Acadêmico, Scielo (Scientific Electronic Library Online) e Portal da Capes, publicações que abordam a presente temática. Diante das análises obtidas, observa-se que o conceito de Educação Ambiental evoluiu ao logo dos anos; os professores, em sua maioria, apresentam resistência em relação à Educação Ambiental na escola; a Educação Ambiental pode ser trabalhada de forma interdisciplinar de diferentes maneiras, embora isso ainda seja pouco utilizado pelas escolas brasileiras.

Palavras-chave: Educação; Meio Ambiente; Escola; Brasil.

Abstract: This article aims to analyze environmental education and its consequences in the Brazilian school context. From the scientific platforms Google Academic, Scielo (Scientific Electronic Library Online) and Portal da Capes, publications that address this topic were selected. Based on the analysis obtained, it is observed that the concept of environmental education has evolved over the years; teachers, for the most part, are resistant to environmental education at school; environmental education can be worked on in an interdisciplinary way in different ways, although this is still little used by Brazilian schools.

Keywords: Education; Environment; School; Brazil.

\footnotetext{
${ }^{1}$ Centro Universitário do Maranhão. E-mail: flaviahelenahbio@hotmail.com. Link para o Lattes: http://lattes.cnpq.br/0831567430191705

2 Universidade Estadual de Campinas. E-mail: lanner4@gmail.com. Link para o Lattes: http://lattes.cnpq.br/7828069698398308

${ }^{3}$ Centro Universitário do Maranhão. E-mail: walter.reis@hotmail.com. Link para o Lattes: http://lattes.cnpq.br/6172775161994038

${ }^{4}$ Centro Universitário do Maranhão. E-mail: rita.miranda@ceuma.br. Link para o Lattes: http://lattes.cnpq.br/1952235749528138
} 


\section{Introdução}

O pensamento sobre as questões ambientais, praticado no âmbito escolar brasileiro, perpassa por avanços e retrocessos quando se considera o objetivo maior da Educação Ambiental, buscando despertar a consciência crítica dos alunos sobre a relação homem e meio ambiente. Além do mais, é crucial compreender que o espaço escolar representa parte de uma rede norteadora de apoio nas discussões socioambientais, que tem como finalidade oferecer um espaço para o desenvolvimento ambientalmente saudável para crianças e adolescentes (APRIGIO et al., 2019).

Segundo o Ministério do Meio Ambiente, a Educação Ambiental (EA) pode ser compreendida como o processo contínuo de formação, de valores e princípios dos indivíduos que guiará suas práticas e seu convívio com o ambiente, com o propósito de que as pessoas assumam uma posição mais responsável frente aos problemas atuais e, por conseguinte, evitem outros futuros problemas socioambientais, tendo em vista que sabemos que o homem nada mais é do que uma parte do meio em que vive. A prática educativa das questões ambientais deve ser integrada, contínua e permanente em todos os níveis e modalidades do ensino formal. $E$, portanto, não deve ser implantada como disciplina específica no currículo de ensino, todavia deve ser inserida como eixo integrador entre todas as disciplinas (BRASIL, 1999).

Nessa perspectiva, é importante destacar que o papel da escola juntamente com a Educação Ambiental é integrar o homem para visar à formação de uma personalidade que busque a vida e a coloque em primeiro lugar, dando proeminência à preservação do meio ambiente. Por isso, é importante que o meio ambiente, a ciência e a educação estejam unidos na construção de uma sociedade comprometida com o cuidado à natureza, visando a garantia da continuidade da geração futura (VIRGENS, 2011).

O empenho de cuidar do meio ambiente é preciso, pois a degradação ambiental, as desigualdades sociais, as mudanças climáticas, os riscos socioambientais globais e o aprofundamento das preocupações com as questões referentes à defesa e proteção do meio ambiente confirmam que o ambiente, sobretudo, o bioma, está extremamente frágil precisando de cuidado (BRASIL, 2013). Por conta disso, precisa-se construir uma sociedade comprometida com o cuidado com o meio ambiente, e a escola é um dos caminhos para que se alcance tal feito.

Nesse sentido, a escola se apresenta como um espaço privilegiado para a prática da Educação Ambiental devendo ser estendida para a comunidade visando estabelecer uma parceria, com a finalidade de promover a formação de cidadãos atuantes globalmente, uma vez que, o que promove e acelera a aprendizagem é o processo que permite aos indivíduos se descobrirem, se identificarem como pessoas capazes de aprender, falar, refletir, contestar, discordar e se expor para defender ideias (KINDEL, 2012; GARCIA, 2014).

Assim, a Educação Ambiental se configura como instrumento de modificação cultural, inserindo no ambiente escolar os conceitos que 
evidenciam que o cuidado com o ambiente seja realizado de forma consciente, e para isso, precisa-se mostrar os impactos causados pela ação do homem ao meio ambiente, buscando construir novas ideias de cuidado e respeito com o mesmo (FERNANDES; ROCHA, 2017).

Nessa perspectiva, a escola deve criar ambientes favoráveis à aprendizagem, para que desperte o interesse dos alunos pelos conteúdos curriculares, estimulando a imaginação, a experimentação, a exploração, seu envolvimento em pesquisa e produção do conhecimento de maneira criativa, em um processo contínuo de inovação, em vez de simplesmente preocupar-se com a apresentação dos conteúdos, tendo o professor ainda como o centro da transmissão do conhecimento, o que provoca um distanciamento entre o ensino e a aprendizagem, dificultando assim todo o processo (MEIRA, 2014).

Vasconcelos e Souto (2003) consideram que, ao se ensinar ciências, é importante não privilegiar apenas a memorização, entretanto deve-se promover situações que possibilitem a formação de um aporte cognitivo significativo para - aluno. Desta forma, as atividades práticas em Educação Ambiental apresentam-se como excelentes recursos que favorecem o processo ensino aprendizagem.

É sabido que a Educação Ambiental precisa ser trabalhada desde a educação infantil para que as crianças desde cedo já comecem a internalizar boas práticas de cuidado com o meio em que vivem. Uma vez que, essas crianças já são capazes de perceber a importância da conservação do meio ambiente e de falar de suas experiências e aprendizagens com familiares e amigos. Desse modo, o trabalho em Educação Ambiental nessa faixa-etária pode ter sucesso, pois nessa fase as crianças estão em formação e disponíveis para aprender (MOURA; CRIBB; JEOVANIO-SILVA, 2016).

Segundo Saheb (2016), para que as crianças sejam estimuladas a construir conhecimentos sobre temáticas socioambientais, deve-se inserir a Educação Ambiental desde a primeira infância, no intuito de superar o senso comum e desenvolver capacidades de sensibilizar, compreender e repensar a problemática socioambiental. Para isso, precisa-se reconhecer as crianças como sujeitos históricos e de direitos que constroem sua identidade pessoal e coletiva por meio das interações, imitações, relações e práticas vivenciadas nos diferentes espaços em que convivem (BRASIL, 2010).

Além disso, torna-se necessário perceber as crianças como seres humanos que vão desenvolvendo cotidianamente, com curiosidade e interesse pela exploração de objetos e atividades que possibilitem experiências interativas com os ambientes de vida, na relação com adultos, outras crianças e seres não humanos (ABREU, 2017).

Diante desta ideia defendida por alguns autores, bem como discutida neste trabalho, a Educação Ambiental é vista como um instrumento de transformação social na busca de um mundo melhor, mais justo, com qualidade de vida e justiça socioambiental. Sendo assim, o presente artigo tem como 
objetivo analisar a Educação Ambiental e seus desdobramentos no contexto escolar brasileiro.

\section{Metodologia}

Trata-se de uma revisão de literatura sistemática com enfoque qualitativo e descritivo, que foi realizada a partir de publicações catalogadas nas plataformas científicas Google Acadêmico, Scielo (Scientific Electronic Library Online) e Portal da Capes, compreendendo o período de 2009 a 2020. Exceto, a unidade que trata da evolução do conceito da Educação Ambiental que se usa publicações a partir de 1976 para que se consiga apresentar as evoluções do conceito ao longo desses anos. O levantamento bibliográfico foi realizado nos meses de setembro e outubro de 2020.

Para a busca das publicações nas bases de dados foram utilizadas as seguintes palavras-chave: "educação", "meio ambiente", "escola" e "Brasil" que foram combinadas entre si para evitar perdas de periódicos relevantes.

Como critério de inclusão adotou-se: publicações completas em português, publicadas a partir de 2009, com temática envolvendo Educação Ambiental nas escolas brasileiras. Podendo as publicações serem quantitativa, qualitativa, exploratória, estudo de caso, ou revisão de literatura.

$\mathrm{Na}$ busca inicial foram analisados os títulos e posteriormente os resumos das publicações para verificar se eram de interesse para a pesquisa. Assim, foram catalogadas 80 publicações referentes à temática estudada. Desse total, após a análise dos títulos obteve-se 50 publicações potencialmente relevantes, posteriormente à análise dos resumos restaram 15 que somadas com as 8 publicações que tratam da evolução do conceito da Educação Ambiental totalizaram 23 publicações que foram divididas em duas unidades para serem discutidas, sendo que a primeira abordou 8 publicações e a segunda 15.

A análise dos dados foi pautada na Educação Ambiental no contexto escolar brasileiro, onde foram verificadas as ideias dos autores apontadas pela literatura. Após a identificação das ideias dos autores, foi feita uma análise crítica das publicações e os resultados foram apresentados na primeira unidade em forma de quadro, e na segunda foram apresentados e discutidos textualmente.

\section{Resultados e discussão}

Para melhor compreensão dos resultados, estes foram agrupados em duas unidades temáticas, são elas: a Educação Ambiental a partir de uma perspectiva conceitual; e, a experiência da Educação Ambiental em escolas brasileiras. 


\section{A Educação Ambiental a partir de uma perspectiva conceitual}

Compreender o conceito de Educação Ambiental assim como seu processo evolutivo, torna-se primordial para o debate sobre as questões ambientais no espaço escolar.

\section{Quadro 1: Evolução Conceitual de Educação Ambiental}

\section{Evolução Conceitual de Educação Ambiental (1976 - 2018)}

"A Educação Ambiental é a ação educativa permanente pela qual a comunidade educativa tem a tomada de consciência de sua realidade global, do tipo de relações que os homens estabelecem entre si e com a natureza, dos problemas derivados de ditas relações e suas causas profundas."

Conferência Sub-regional de Educação Ambiental para a Educação Secundária - Chosica, Peru em 1976.

"A Educação Ambiental é um processo de reconhecimento de valores e clarificações de conceitos, objetivando o desenvolvimento das habilidades e modificando as atitudes em relação ao meio, para entender e apreciar as inter-relações entre os seres humanos, suas culturas e seus meios biofísicos."

Conferência Intergovernamental de Tbilisi, Geórgia em 1977.

"Consideramos que a Educação Ambiental para uma sustentabilidade equitativa é um processo de aprendizagem permanente, baseado no respeito a todas as formas de vida. Tal educação afirma valores e ações que contribuem para a transformação humana e social e para a preservação ecológica."

Tratado de Educação Ambiental para Sociedades Sustentáveis e Responsabilidade Global. Documento da sociedade civil durante a RIO-92.

"Um processo educativo eminentemente político, que visa ao desenvolvimento nos educandos de uma consciência crítica acerca das instituições, atores e fatores social geradores de riscos e respectivos conflitos socioambientais."

LAYRARGUES; P.P. Crise ambiental e suas implicações na educação, 2002.

"Processo em que se busca despertar a preocupação individual e coletiva para a questão ambiental, garantindo o acesso à informação em linguagem adequada, contribuindo para o desenvolvimento de uma consciência crítica e estimulando o enfrentamento das questões ambientais e sociais."

MOUSINHO, P. Glossário. In: Trigueiro, A. (Coord.) Meio ambiente no século 21. Rio de Janeiro: Sextante, 2003.

"A Educação Ambiental nasce como um processo educativo que conduz a um saber ambiental materializado nos valores éticos e nas regras políticas de convívio social e de mercado, que implica a questão distributiva entre benefícios e prejuízos da apropriação e do uso da natureza."

SORRENTINO, M. et al. Educação Ambiental como política pública. Educação e pesquisa, v. 31, p. 285-299, 2005.

"É um aprendizado social, usado na comunicação para solucionar problemas por meio da interação e do processo de recriação e reinterpretação, de informações e conceitos, que advém tanto da experiência pessoal, quanto dos conhecimentos obtidos em sala de aula."

COLOMBO, S. R. A Educação Ambiental como instrumento na formação da cidadania. Rev. Brasileira de Pesquisa em Educação em Ciências, [S. I.], v. 14, n. 2, p. 067-075, 2014.

"O propósito de todo o esforço empregado na Educação Ambiental é gerar conhecimento capaz de reduzir o impacto que as interações humanas provocam no meio-ambiente, considerando neste contexto as demandas sociais por desenvolvimento."

FERNANDES, J. G. Educação Ambiental: O que é, Conceitos e Significado. 2018. Disponível em: $<$ https://fia.com.br/blog/educacao-ambiental/>. Acesso em: 12 setembro de 2020.

Fonte: Os Autores (2020). 
No (Quadro 1) foram apresentadas enunciações de pesquisadores que se destacam no estudo da Educação Ambiental e que serão discutidas a seguir.

Em 1976, na Conferência Sub-regional de Educação Ambiental para a Educação Secundária (Quadro 1), registravam-se os primeiros documentos que consolidariam, nas décadas seguintes, a questão ambiental na esfera educacional. De acordo com esse documento (1976, n. p.):

\begin{abstract}
A Educação Ambiental desenvolve, mediante uma prática que vincula o educando com a comunidade, valores e atitudes que promovem um comportamento dirigido a transformação superadora dessa realidade, tanto em seus aspectos naturais como sociais, desenvolvendo no educando as habilidades e atitudes necessárias para dita transformação.
\end{abstract}

Já em 1977, na Conferência Intergovernamental de Tbilisi, a EA tinha como pilar o desenvolvimento das habilidades e atitudes do homem em relação ao meio com ênfase na cultura e no ambiente biofísico. A Educação Ambiental também está relacionada com a prática das tomadas de decisões e a ética que conduzem para a melhora da qualidade de vida (TBILISI, 1977).

Décadas depois, o discurso sobre EA já se encontrava atrelado ao conceito de sustentabilidade, caracterizado por um processo de aprendizagem destacou-se por ser o mais importante encontro, até aquele momento, sobre o meio ambiente. Nesse evento se reuniram 170 países no Rio de Janeiro e na ocasião o Tratado da Educação Ambiental para Sociedades Sustentáveis foi formulado. A Rio-92 (1992, n. p.) foi de fato importante e considera que:

A Educação Ambiental estimula a formação de sociedades socialmente justas e ecologicamente equilibradas, que conservam entre si relações de interdependência e diversidade. "Isto requer responsabilidade individual e coletiva em níveis local, nacional e planetário".

Nessa perspectiva, Layrargues (2002) sugere uma busca por uma estratégia pedagógica do enfrentamento dos conflitos socioambientais a partir de meios coletivos de exercício da cidadania, pautados na criação de demandas por políticas públicas participativas conforme requer a gestão ambiental democrática.

Desse modo, corroborando com as ideais citadas anteriormente e conforme é possível observar no (Quadro 1), a Educação Ambiental desenvolve-se num contexto de complexidade, procurando trabalhar não apenas a mudança cultural, mas também a transformação social, assumindo a crise ambiental como uma questão ética e política (MOUSINHO, 2003). 
Sorrentino (2005) conceitua Educação Ambiental na perspectiva de direcioná-la para a cidadania considerando seu sentido de pertencimento e corresponsabilidade que, por meio da ação coletiva e organizada, busca a compreensão e a superação das causas estruturais e conjunturais dos problemas ambientais que tem comprometido a qualidade de vida da humanidade.

Além disso, Colombo (2014) relata que a EA deve ser entendida como qualquer outra área de conhecimento. Visto que ela precisa ser assumida de forma socioambiental, pois o próprio conceito de meio ambiente vem passando por mudanças, deixando de ser somente os aspectos físicos e biológicos, sendo incluídos também os conceitos econômicos e socioculturais, bem como suas interações.

Por fim, para Fernandes (2018), em sentido abrangente, o termo Educação Ambiental define a forma como são transmitidos entre as gerações os valores, costumes e hábitos no manejo eficiente dos elementos que rodeiam ou envolvem os seres vivos. Com base nessa definição, o tema se completa pela percepção da necessidade de estabelecimento de um processo continuado e de criação e comunicação de conhecimento. Tudo isso para que se possa promover o surgimento de sociedades mais justas e ecologicamente equilibradas.

Nota-se que o conceito de Educação Ambiental evoluiu bastante ao longo dos anos. Percebe-se ainda que muita coisa já melhorou, entretanto muito ainda está por melhorar e, a escola se estabelece como uma grande parceira nesse processo da Educação Ambiental.

\section{A experiência da Educação Ambiental em escolas brasileiras}

Com base no levantamento bibliográfico realizado, tem-se que a Educação Ambiental no espaço escolar vem se destacando significativamente no Brasil, principalmente nas últimas décadas. Esse processo segue atrelado tanto aos ambientes formais como informais, e nesse sentido, Higuchi e Maroti (2014, p. 97) acreditam que a EA não se limita somente a um lugar específico, mas que pode estar em vários deles com várias formas de interação.

Nesse sentido, Cuba (2010, p. 23) aponta a escola como um lugar privilegiado, pois estabelece um link de informações que possibilitam condições alternativas e estimula uma postura do cidadão, que estará ciente de suas responsabilidades e de que também é parte do meio ambiente. Por isso, é essencial que a escola seja um espaço influente que ajude no desenvolvimento de valores e atitudes tanto social quanto ecológica.

Segundo Batista e Paula (2014) a Educação Ambiental no processo de aprendizagem, proporciona o desenvolvimento de um pensamento reflexivo, traduzido na troca de conhecimento, corroborando para a valorização dos

ambientes educacionais. Para o aluno, proporciona uma visão crítica e 
formadora de opinião. Seguindo o raciocínio, Chaves e Gaia (2013) consideram a escola como o lugar onde acontece a sensibilização quanto às questões ambientais. Mesmo que essas questões estejam fora dela é possível trabalhar esse conhecimento e dar continuidade a ações ambientais, formar cidadão mais sensibilizado sobre a temática ambiental.

Desta forma, considerando-se que a principal função da EA, seja contribuir para a formação de cidadãos conscientes e críticos, capazes de decidirem e atuarem na realidade socioambiental de um modo comprometido com a vida, com o bem-estar de cada um e da sociedade, é pertinente afirmar que a EA assume uma ampla dimensão, atingindo praticamente todas as áreas do currículo, podendo ser compreendida com um sinônimo do que se entende, por educação escolar (FAHT, 2011, p. 18).

Mas a EA também é uma forma de educação política e se constitui como uma complexa visão do mundo social (SOUSA, 2018). Como em toda essa relevância sobre a temática ambiental há um destaque especial para a escola, como espaço para a implementação das atividades voltadas para a reflexão sobre o meio ambiente. Existe uma demanda para atividades dentro e fora da escola tais como atividades de campo e projetos ambientais. Dessa maneira, ocorre uma participação maior do aluno, o que leva a autoconfiança, melhores atitudes e um comprometimento com a proteção ambiental (CHẢES; GAIA, 2013).

[...] um projeto pequeno em uma escola no qual envolva somente um grupo de alunos e um professor orientador, não é suficiente para mudar a mentalidade de toda uma escola, sendo assim, de toda uma comunidade, não sendo considerada assim, uma verdadeira Educação Ambiental (CHAVES; GAIA, 2013, p. 7).

Dentro deste contexto, deve haver uma produção de conhecimento que complete as inter-relações do meio natural e social, bem como o papel da escola, para priorizar um novo perfil de crescimento, com ênfase na sustentabilidade socioambiental (BERNARDES; NEHME, 2017).

Por isso, Chaves e Gaia (2013) consideram que a evolução da EA deve ser contínua e permanente, havendo sensibilização por parte do professor, já que é o principal agente transformador da escola. Assis (2013) complementa a ideia anterior, e diz que os educadores ambientais exercem um papel importante na sociedade como formadores de opinião, com propostas pedagógicas para desenvolver a percepção do ambiente e das relações humanas sob vários aspectos culturais e sociais. Assim, se torna inegável a participação dos professores e seus diversos saberes adquiridos durante sua formação acadêmica, através de cursos de capacitação e de projetos, sempre de forma continuada, para desenvolver novas formas de propostas pedagógicas. 
Através de uma pesquisa com estudantes do ensino médio de escolas públicas e particulares da cidade de Canoas-RS, Silva et al. (2020) observaram que os jovens se preocupam com os problemas do ambiente e acreditam que a ciência é capaz de solucionar alguns deles, porém não demonstram otimismo em relação ao futuro do planeta. Já Vittorazzi e Silva (2020) realizaram seus estudos com alunos do $4^{\circ}$ ano do Ensino Fundamental de uma escola municipal de Vitória-ES e, identificaram a importância de algumas estratégias no sentido de promover uma visão articulada de caráter globalizante, onde o meio é integrado pelo ambiente e pela sociedade.

Para haver eficiência na conscientização sobre a Educação Ambiental é necessário que haja uma participação ativa do aluno na organização de sua aprendizagem. Uma reflexão sobre as importantes questões ambientais. De acordo com Colombo (2014, p. 73):

[...] afinal o lixo não desaparece quando é jogado na lixeira. Sendo assim há de se buscar formas atrativas de envolvê-los nos reais problemas da comunidade em que vivem, favorecendo o protagonismo juvenil.

Nesse prisma, a Educação Ambiental tem encontrado incontáveis desafios, como problemas históricos, vistos somente pela área de Ciências Naturais ou alguns campos da Biologia. Infelizmente, há casos em que a escola somente repassa informações básicas sobre as questões ambientais, sem levar em conta a interdisciplinaridade e o envolvimento da comunidade (CHAVES; GAIA, 2013).

Tal fato pode ser explicado por Profice (2016), pois quando se fala em Educação Ambiental, os professores das diferentes áreas do conhecimento mesmo reconhecendo a necessidade da Educação Ambiental, a maioria apresenta certa inabilidade ou resistência; exceto os das áreas de ciências naturais e geografia, nos quais normalmente se encontra uma atitude mais proativa sobre a questão.

Nesse sentido, Aguiar et al. (2017) complementam relatando que a efetivação da Educação Ambiental ainda tem se mostrado um grande desafio no cenário brasileiro. Essa dificuldade não decorre apenas da formação do professor de cada disciplina, mas, sobretudo, da baixa frequência de trabalho interdisciplinar entre os educadores, o desânimo diante da atividade docente e da realidade que o professor enfrenta na sala de aula, a realidade das escolas que frequentemente não adotam a Educação Ambiental como uma prioridade quando constroem ou reformulam o Projeto Político Pedagógico, e ainda, o pouco apoio obtido das esferas governamentais no disponibilizar recursos didáticos ou financeiros para a efetivação de atividades diferenciadas com os alunos ou mesmo para a formação continuada do professor.

Diante dessas dificuldades encontradas, Cuba (2010) propõe que a EA deva ser estudada no modo científico, passada com uma disciplina específica,

revista brasileira educação ambiental 
mas sem perder a natureza interdisciplinar. Ainda segundo o autor, a EA pode ser utilizada como uma disciplina inserida para ajudar no estudo de problemas ambientais, encaixada no currículo escolar. Mas deverá propor aplicações, tratando em um tema de interesse dos alunos, e não somente como mais uma proposta pedagógica, como tem ocorrido em muitas escolas brasileiras.

Nesse sentido, Aguiar et al. (2017) expõem que a Educação Ambiental pode ser trabalhada através de diferentes linguagens, recursos didáticos e mecanismos com objetivos e metodologias pré-definidos, não se restringindo apenas à sala de aula, diferente disso, pode fazer uso da música, da pintura, da poesia, do desenho, dos quadrinhos, da encenação teatral, do vídeo, dos esportes, da experiência da reutilização de materiais descartados, da aula de campo, do texto jornalístico, de softwares, da internet, dentre tantos outros recursos. Levando sempre em consideração que o aluno não é um vaso vazio a ser abarrotado de informações, todavia é um ser dotado de experiências cotidianas que devem ser aproveitadas e retrabalhadas para a finalidade desejada.

O desejo de que haja um espaço específico, para que essas questões inegavelmente importantes sejam tratadas, reflete a busca por um espaço curricular próprio que forme um eixo capaz de reunir e articular o currículo e os elementos orientadores da ação do professor. Parece que o desejo aí contido não é a criação de uma disciplina em si mesma, mas sim, o de encontrar uma alternativa que viabilize a inserção do ambiental no currículo, pois esse é o modelo que conhecemos e ao qual estamos familiarizados (SANTOS; SANTOS, 2016, p. 371).

Desta forma, a escola se torna o melhor lugar para desenvolver ações reflexivas, que podem ocorrer entre um grupo de pessoas, baseada na troca de conhecimentos que se dá através de atividades pedagógicas desenvolvidas (BATISTA; PAULA, 2014). A EA deve ser percebida como um processo de construção do conhecimento. Um trabalho lúdico, expansivo e dinâmico que contribui para o saber das pessoas envolvidas (LOPES; BISPO; CARVALHO, 2009).

\section{Conclusões}

Diante do exposto, observa-se que o conceito de Educação Ambiental evoluiu bastante ao longo dos anos, entretanto muitas questões relacionadas ao meio ambiente ainda não se dissolveram, apesar dos avanços que já se obteve na área de Educação Ambiental.

A respeito da Educação Ambiental no âmbito escolar, nota-se que ela é de extrema relevância, pois através dela é possível observar uma efetiva mudança de hábitos em toda a sociedade, e é pelo desenvolvimento do saber ambiental que se formam cidadãos mais conscientes e críticos de seus atos em relação ao ambiente que os cercam. Nesse contexto, a escola carrega consigo 
uma missão fundamental e estratégica de se tornar a maior auxiliadora na busca da conscientização e preservação do meio ambiente.

Em relação à prática da Educação Ambiental no contexto educacional brasileiro, tem-se que muitos professores se apresentam resistentes em relação a esta temática, exceto os professores de biologia e geografia, estes por sua vez se apresentam mais proativos no trabalho com a Educação Ambiental na escola. Outra questão observada foi a carência do trabalho interdisciplinar realizado entre os professores em relação à Educação Ambiental, dificultando todo o processo.

A partir deste estudo, pode-se perceber ainda que a Educação Ambiental pode e deve ser trabalhada de diferentes formas, não se limitando à sala de aula, mas podendo fazer uso de recursos como a música, a dança, o teatro, a aula de campo, o passeio nos arredores da escola, enfim, buscar se aproximar da realidade do aluno por meio da prática, não ficando apenas na teoria tratada em sala de aula.

Portanto, com as considerações desenvolvidas espera-se contribuir para a evolução das discussões sobre a Educação Ambiental no cenário brasileiro e, ao mesmo tempo, possa abrir espaço para que soluções práticas sejam alcançadas, e com isso, a Educação Ambiental no contexto escolar seja vista como algo relevante que muda a vida das pessoas, da escola, da comunidade, do planeta.

Agradecimentos: À Universidade Ceuma como suporte institucional para a realização desta pesquisa.

\section{Referências}

ABREU, M.J.M. O diálogo da educação física com a Educação Ambiental na educação infantil: um processo de formação de docentes na rede municipal de ensino de Curitiba. Tese (Doutorado em Educação) - Programa de PósGraduação em Educação, Universidade Federal do Paraná, Curitiba, 2017.

AGUIAR, P.C.B. et al. Da teoria à prática em Educação Ambiental. Revista Gestão \& Sustentabilidade Ambiental, v. 6, n. 2, p. 111-132, 2017.

APRIGIO, S.S.O. et al. Abordagem ambiental no âmbito escolar: percepções dos alunos sobre as práticas socioambientais durante 0 ensino médio. Pesquisa em Foco, v. 24, n. 1, 2019.

ASSIS, A.R.S. Discussão Crítica Sobre Educação Ambiental e o Ensino de Biologia para a Prática Social. Revista Eletrônica do Curso de GeografiaCampus Jataí- UFG,n.21, Jul.- Dez./ 2013.

BATISTA. D.F; PAULA. M.C. Considerações Teóricas Sobre Práticas de Educação Ambiental, nas Escolas Brasileiras: Conceito, Trajetória, Inclusão e Aplicação. Revista Terceiro, Incluído v. 4, n. 1. Jan./Jun., 2014 
BERNARDES, M.B.J; NEHME, V.G.F. A PESQUISA-AÇÃO: mediadora de ações em Educação Ambiental. Espaço em Revista, v. 19, n. 2, p. 56-67, 2017.

BRASIL. Lei Federal n. 9.795, de 27 de abril de 1999. Disponível em:<http://www.planalto.gov.br/ccivil 03/leis/L9795.htm> Acessado em: 21 de set. 2020.

BRASIL. Secretaria de Educação Fundamental. Parâmetros Curriculares Nacionais.Introdução aos Parâmetros Curriculares/ Secretaria de Educação Fundamental.Brasília: MEC, 1997.

BRASIL. Ministério de Educação. Diretrizes Curriculares Nacionais para a Educação Infantil. Ministério da Educação. Secretaria de Educação Básica. Brasília, DF: MEC; SEB, 2010.

BRASIL. Diretrizes curriculares nacionais gerais da Educação Básica. Brasília: MEC, SEB, DIVEI, p. 562, 2013.

CARDOSO, K. M. M. Educação Ambiental nas escolas. p. 1-27, Brasília, 2011.

CHAVES, R. A; GAIA, M.C.M. O papel da escola na construção da Educação Ambiental: ações e reflexões, Município de Contagem, Minas Gerais, 2013.

COLOMBO, S. R. A Educação Ambiental como instrumento na formação da cidadania. Rev. Brasileira de Pesquisa em Educação em Ciências, [S. I.], v. 14, n. 2, p. 067-075, 2014.

TBILISI. Conferência Intergovernamental Sobre Educação Ambiental.Tbilisi, Georgia, ex- URSS, de 14 a 26 de outubro de 1997. Publicação de Meio Ambiente e desenvolvimento: Documentos Oficiais. Secretaria do Meio Ambiente -Coordenadoria de Educação Ambiental. SP, 1993.

CUBA, M. A. Educação Ambiental nas escolas. ECCOM, v.1, n. 2, p. 23-31, Jul./Dez., 2010.

FAHT, E. C. Diagnóstico e análise de atividades relacionadas à Educação Ambiental em escolas públicas de São Paulo- Universidade de São PauloSP e Blumenau-SC - São Paulo, 2011.

FERNANDES, J. G. Educação Ambiental: O que é, Conceitos e Significado. 2018. Disponível em: <https://fia.com.br/blog/educacao-ambiental/>. Acesso em: 12 setembro de 2020.

FERNANDES, P. R.; ROCHA, P. C. Coleta seletiva e escolas municipais: uma parceria possível através da Educação Ambiental. Estudo de caso: Escolas municipais da Estância Turística de Olímpia. 8ํㅜ Fórum Internacional de Resíduos Sólidos, Curitiba. Anais... Curitiba, PR, 2017. 
GARCIA, O.G. Um sonho querido. Revista Carta na escola, № 84, p.24-25, 2014.

HIGUCHI, M.I.G.; MAROTI, P.S. Espacialidades e socialidades da Educação Ambiental além dos muros da escola. Pesquisa em Educação Ambiental, v. 9, n. 1, p. 95-109, 2014.

KINDEL, E.A.I. Educação Ambiental: da teoria a prática. Porto Alegre: Mediação,144 p., 2012.

LOPES, W.; BISPO, W; CARVALHO J. Educação Ambiental Nas Escolas: Uma Estratégia De Mudança. p. 1-15. TO, 2009.

LOUREIRO, C.F.B.; LAYRARGUES, P.P.; CASTRO, R.S. (orgs.). Educação Ambiental: repensando o espaço da cidadania. - 3. ed. - São Paulo: Cortez, 2005.

LOUREIRO C. F. B. Educação Ambiental no Brasil. p. 3-13, Rio de Janeiro, 2008.

MEIRA, L. Cultura digital e Ensino Médio. Revista Pátio ensino médio, ano 5, n.19. p. 6-9. 2014.

MOURA, J.S.T.; CRIBB, S.L.S.P.; JEOVANIO-SILVA, A.L. Vivência de atividades práticas e lúdicas na Educação Ambiental de crianças de 4-5 anos: o despertar da consciência ecológica e estímulo á motivação profissional e interação aluno-professor. Revista Brasileira de Educação Ambiental (RevBEA), v. 11, n. 1, p. 361-384, 2016.

MOUSINHO, P. GLOSSÁRIO. In: Trigueiro, A. (Coord.) Meio Ambiente no século 21. Rio de Janeiro, Ed. Sextante. 2003.

OLIVEIRA, G.C.S; TONIOSSO, J.P. Educação Ambiental: Práticas Pedagógicas na Educação Infantil. Cadernos de Educação: Ensino e Sociedade, São Paulo, v. 1, n. 1, p. 30-43, 2014.

PROFICE, C.C. Educação Ambiental: dilemas e desafios no cenário acadêmico brasileiro. REDE - Revista Eletrônica do PRODEMA, Fortaleza, Brasil, v. 10, n. 1, p.22-37, 2016.

SAHEB, D. A Educação Ambiental na Educação Infantil. Revista Eletrônica do Mestrado em Educação Ambiental, v. 1, p. 133-158, 2016.

SANTOS, A.G.; SANTOS, A.P. Inserção da Educação Ambiental no Currículo Escolar. Revista Monográficas Ambientais - REMOA, v. $15 \mathrm{n}, 1$, Jan- Abr. 2016 p. 369-380.

SILVA, C.S.S. et al. Pesquisa de Percepções de Estudantes do Ensino Médio sobre os Desafios Ambientais. Ciência \& Educação (Bauru), v. 26, 2020.

SORRENTINO, M. et al. Educação Ambiental como política pública. Educação e Pesquisa, v. 31, p. 285-299, 2005. 
SOUSA, P.C.O. Educação Ambiental nas escolas: uma revisão da literatura. 2018. 30 f. Trabalho de Conclusão de Curso de Licenciatura em Ciências Biológicas, Faculdade Araguaia, Goiânia-GO, 2018.

UNESCO. Década das Nações Unidas da Educação para o Desenvolvimento Sustentável - Brasília, mar. 2005-2014. p.120.

VASCONCELOS, S.D; SOUTO, E. O livro didático de ciências no ensino fundamental - proposta de critérios para análise do conteúdo zoológico. Ciência \& Educação, v. 9, p. 93-104. 2003.

VEREDAS. Educação Ambiental para a Cidadania, Instrumento de Realização do Direito a um Meio, Belo Horizonte, v.13, n. 27, p. 291-314, 2016.

VIRGENS, R. D. A. A Educação Ambiental no ambiente escolar. Brasília, 2011.

VITTORAZZI, D.L.; SILVA, A. As representações do ensino de ciências de um grupo de professores do ensino fundamental: implicações na formação científica para a cidadania. Ensaio Pesquisa em Educação em Ciências (Belo Horizonte), v. 22, 2020. 